\title{
Experimental Organism Malignant Ependymoma
}

National Cancer Institute

\section{Source}

National Cancer Institute. Experimental Organism Malignant Ependymoma. NCI

Thesaurus. Code C119575.

A malignant neoplasm of ependymal origin. 